\title{
Antibacterial activities and antioxidant capacity of Aloe vera
}

Fatemeh Nejatzadeh-Barandozi

\begin{abstract}
Background: The aim of this study was to identify, quantify, and compare the phytochemical contents, antioxidant capacities, and antibacterial activities of Aloe vera lyophilized leaf gel (LGE) and 95\% ethanol leaf gel extracts (ELGE) using GC-MS and spectrophotometric methods.

Results: Analytically, 95\% ethanol is less effective than ethyl acetate/diethyl ether or hexane (in the case of fatty acids) extractions in separating phytochemicals for characterization purposes. However, although fewer compounds are extracted in the ELGE, they are approximately 345 times more concentrated as compared to the LGE, hence justifying ELGE use in biological efficacy studies in vivo. Individual phytochemicals identified included various phenolic acids/polyphenols, phytosterols, fatty acids, indoles, alkanes, pyrimidines, alkaloids, organic acids, aldehydes, dicarboxylic acids, ketones, and alcohols. Due to the presence of the antioxidant polyphenols, indoles, and alkaloids, the A. vera leaf gel shows antioxidant capacity as confirmed by ORAC and FRAP analyses. Both analytical methods used show the non-flavonoid polyphenols to contribute to the majority of the total polyphenol content. Three different solvents such as aqueous, ethanol, and acetone were used to extract the bioactive compounds from the leaves of $A$. vera to screen the antibacterial activity selected human clinical pathogens by agar diffusion method. The maximum antibacterial activities were observed in acetone extracts $(12 \pm 0.45,20 \pm 0.35$, $20 \pm 0.57$, and $15 \pm 0.38 \mathrm{~nm}$ ) other than aqueous and ethanol extracts.
\end{abstract}

Conclusion: Due to its phytochemical composition, A. vera leaf gel may show promise in alleviating symptoms associated with/or prevention of cardiovascular diseases, cancer, neurodegeneration, and diabetes.

Keywords: Aloe vera; Antibacterial activities; Antioxidant capacity; Gas chromatography; Mass spectrometry

\section{Background}

Aloe vera (L.) Burm.f. (Aloe barbadensis Miller) is a perennial succulent xerophyte, which develops water storage tissue in the leaves to survive in dry areas of low or erratic rainfall. The innermost part of the leaf is a clear, soft, moist, and slippery tissue that consists of large thin-walled parenchyma cells in which water is held in the form of a viscous mucilage [1]. Therefore, the thick fleshy leaves of aloe plants contain not only cell wall carbohydrates such as cellulose and hemicellulose but also storage carbohydrates such as acetylated mannans [2].

$A$. vera has been used for many centuries for its curative and therapeutic properties, and although over 75 active ingredients from the inner gel have been identified, therapeutic effects have not been correlated well with each

Correspondence: fnejatzadeh@yahoo.com

Department of Horticulture, Faculty of Agriculture, Khoy Branch, Islamic Azad University, P.O. Box 58168-44799, Khoy, Iran individual component [3]. Many of the medicinal effects of aloe leaf extracts have been attributed to the polysaccharides found in the inner leaf parenchymatous tissue $[4,5]$, but it is believed that these biological activities should be assigned to a synergistic action of the compounds contained therein rather than a single chemical substance [6]. A. vera is the most commercialized aloe species, and processing of the leaf pulp has become a large worldwide industry. In the food industry, it has been used as a source of functional foods and as an ingredient in other food products, for the production of gel-containing health drinks and beverages. In the cosmetic and toiletry industry, it has been used as base material for the production of creams, lotions, soaps, shampoos, facial cleansers, and other products. In the pharmaceutical industry, it has been used for the manufacture of topical products such as ointments and gel preparations, as well as in the production of tablets and capsules $[7,8]$. Important

\section{穴}


pharmaceutical properties that have recently been discovered for both the $A$. vera gel and whole leaf extract include the ability to improve the bioavailability of coadministered vitamins in human subjects [9]. Due to its absorption enhancing effects, $A$. vera gel may be employed to effectively deliver poorly absorbable drugs through the oral route of drug administration. Furthermore, the dried powder obtained from $A$. vera gel was successfully used to manufacture directly compressible matrix-type tablets. These matrix-type tablets slowly released a model compound over an extended period of time and thereby showing potential to be used as an excipient in modified release dosage forms [10].

Apart from Aloe being used extensively in the cosmetic industry, it has been described for centuries for its laxative, anti-inflammatory, immunostimulant, antiseptic [11], wound and burn healing [12], antiulcer [13], antitumor [14], and antidiabetic [15] activities. These treatments are based on anecdotal evidence or research findings done almost exclusively on $A$. vera. Different Aloe species would have various phytochemical contents, health benefits, and possible toxicities. Hence, it is of relevance for scientists, industry, and rural communities not only to research the relevant medicinal uses of their indigenous Aloe species but also to determine the active components and their individual or combined mechanisms of biological function. The use of $95 \%$ ethanol extracts of various Aloe species is extensively described in the literature for determining biological activity in the treatment and prevention of a variety of health conditions [16,17], in particular, diabetes [18,19]. In this study, we determined and compared the phytochemical contents and antioxidant capacities, antibacterial activities of $A$. vera lyophilized leaf gel and 95\% ethanol leaf gel extracts using gas chromatography-mass spectrometry (GC-MS) and spectrophotometric methods of analysis. This was done not only to describe $A$. vera leaf gel extracts with regard to phytochemical contents and possible health benefits but also to compare various extraction methods for both analytical efficacy and possible biological relevance.

\section{Methods}

\section{Samples}

Whole, freshly cut, A. vera leaves $(100 \mathrm{~kg})$ were harvested in the month of September from farms in the National Institute of Genetic Engineering and Biotechnology (NIGEB), Tehran of Iran. The inner leaf gel was removed, homogenized, freeze-dried, and stored at $-20^{\circ} \mathrm{C}$ until analysis. This was termed the leaf gel extract (LGE) for the purpose of this study. Approximately half of the LGE was used for the preparation of a 95\% ethanol extract as described previously [19]. This was termed the $95 \%$ ethanol leaf gel extract (ELGE).

\section{Material}

All analytical standards were purchased from SigmaAldrich (St. Louis, MO, USA), and phenol reagent and other reagent chemicals and all of the organic solvents used were of ultrahigh purity which were purchased from Merck (Darmstadt, Germany).

\section{Ethyl acetate/diethyl ether extraction}

The internal standard, 3-phenylbutyric acid (25 mg/50 mL), was added to $25 \mathrm{mg}$ of finely ground LGE and ELGE, followed by the addition of $1 \mathrm{~mL}$ of sodium acetate buffer $(0.125 \mathrm{M})$. $\beta$-Glucuronidase $(30 \mu \mathrm{L})$ was added, and the sample was vortexed and incubated overnight at $37^{\circ} \mathrm{C}$. The sample was extracted with $6 \mathrm{~mL}$ of ethyl acetate followed by $3 \mathrm{~mL}$ of diethyl ether. The organic phase was collected after each extraction via centrifugation. The organic phase from each extraction was pooled and dried under nitrogen. The dried extract was derivatized with bis(trimethylsilyl) trifluoroacetamide (BSTFA, $100 \mu \mathrm{L}$ ), trimethylchlorosilane (TMCS, $20 \mu \mathrm{L}$ ), and pyridine $(20 \mu \mathrm{L})$ at $70^{\circ} \mathrm{C}$ for $30 \mathrm{~min}$. After cooling, $0.1 \mu \mathrm{L}$ of the extract was injected into the GC-MS via splitless injection.

\section{Fatty acid extraction}

Heptadecanoic acid (72 mM), as an internal standard, was added to $25 \mathrm{mg}$ of LGE and ELGE followed by $100 \mu \mathrm{L}$ of a 45-mM solution of butylated hydroxytoluene and $2 \mathrm{~mL}$ of methanolic $\mathrm{HCl}(3 \mathrm{~N})$. The samples were then vortexed and incubated for $4 \mathrm{~h}$ at $90^{\circ} \mathrm{C}$. After cooling to room temperature, the sample was extracted twice with $2 \mathrm{~mL}$ of hexane, dried under a nitrogen stream, and finally resuspended with $100 \mu \mathrm{L}$ of hexane, $1 \mu \mathrm{L}$ of which was injected onto the GC-MS via splitless injection.

\section{Gas chromatography-mass spectrometry}

An Agilent 6890 GC ported to a 5973 mass selective detector (Santa Clara, CA, USA) was used for the identification and quantification of individual fatty acids. For the acquisition of an electron ionization mass spectrum, an ion source temperature of $200^{\circ} \mathrm{C}$ and electron energy of $70 \mathrm{eV}$ were used. The gas chromatograph was equipped with an SE-30 capillary column (Agilent), a split/splitless injection piece $\left(250^{\circ} \mathrm{C}\right)$, and direct GC-MS coupling $\left(260^{\circ} \mathrm{C}\right)$. Helium $(1 \mathrm{~mL} / \mathrm{min})$ was used as the carrier gas. The oven temperature program for analyzing the ethyl acetate/diethyl ether extract was an initial oven temperature of $40^{\circ} \mathrm{C}$ and was maintained for $2 \mathrm{~min}$, followed by a steady climb to $350^{\circ} \mathrm{C}$ at a rate of $5^{\circ} \mathrm{C} / \mathrm{min}$. For the fatty acid analysis, an initial oven temperature of $50^{\circ} \mathrm{C}$ was maintained for 1.5 min and then allowed to increase to $190^{\circ} \mathrm{C}$ at a rate of $30^{\circ} \mathrm{C} / \mathrm{min}$. The oven temperature was maintained at $190^{\circ} \mathrm{C}$ for $5 \mathrm{~min}$ and then allowed to increase to $220^{\circ} \mathrm{C}$ at a rate of $8^{\circ} \mathrm{C} / \mathrm{min}$. The oven temperature was again maintained for $2 \mathrm{~min}$ and finally ramped to $230^{\circ} \mathrm{C}$ at a 
rate of $3^{\circ} \mathrm{C} / \mathrm{min}$ and maintained for $24 \mathrm{~min}$ at this temperature.

\section{Total polyphenol assay}

The total polyphenol content of the extracts were determined according to the Folin-Ciocalteu procedure [20]. Briefly, $10 \mathrm{mg}$ of finely ground LGE or ELGE was dissolved in $200 \mu \mathrm{L}$ of $\mathrm{H} 2 \mathrm{O}$ in a test tube followed by 1 $\mathrm{mL}$ of Folin-Ciocalteu's reagent. This was allowed to stand for $8 \mathrm{~min}$ at room temperature. Next, $0.8 \mathrm{~mL}$ of sodium carbonate $(7.5 \%, w / v)$ was added, mixed, and allowed to stand for $30 \mathrm{~min}$. Absorption was measured at $765 \mathrm{~nm}$ (Shimadzu UV-1601 spectrophotometer, Kyoto, Japan). The mean total phenolic content $(n=3)$ was expressed as milligrams of gallic acid (Sigma-Aldrich) equivalents per $100 \mathrm{~g}$ of wet and dry mass (mg of GAE/ $100 \mathrm{~g}$ ) (standard deviation (SD)).

\section{Total flavonoid assay}

The total flavonoid content was measured using the $\mathrm{AlCl} 3$ colorimetric assay [21] with some modifications. Briefly, $10 \mathrm{mg}$ of LGE or ELGE was dissolved in $1 \mathrm{~mL}$ of $\mathrm{H} 2 \mathrm{O}$, to which $60 \mu \mathrm{L}$ of $5 \%(w / v)$ NaNO2 was added. After $5 \mathrm{~min}$, $60 \mu \mathrm{L}$ of a $10 \%(w / v) \mathrm{AlCl} 3$ was added. In the sixth minute, $400 \mu \mathrm{L}$ of $1 \mathrm{M} \mathrm{NaOH}$ was added, and the total volume was made up to $2 \mathrm{~mL}$ with $\mathrm{H}_{2} \mathrm{O}$. The solution was mixed well, and the absorbance was measured at $510 \mathrm{~nm}$ against a reagent blank. Concentrations were determined using a catechin (Sigma-Aldrich) solution standard curve. The mean total flavonoid content $(n=3)$ was expressed as milligrams of catechin equivalents (CE) per $100 \mathrm{~g}$ of wet and dry mass (mg of CE/100 g) (SD).

\section{Oxygen radical absorbance capacity}

Oxygen radical absorbance capacity (ORAC) analyses of hydrophilic and lipophilic compounds in LGE and ELGE were performed as described previously [22]. The analysis of lipophilic compounds was aided by the addition of randomly methylated $\beta$-cyclodextrin as a solubility enhancer as described before [23]. Briefly, in a volume of $200 \mu \mathrm{L}$, the reaction contained 56-nM fluorescein (Sigma-Aldrich) as a target for free radical attack by 240-nM 2,2'-azobis(2-amidinopropane)dihydrochloride (Sigma-Aldrich). A BioTEK fluorescence plate reader (FL-600, Winooski, VT, USA) was used, and the decay of fluorescence of fluorescein (excitation, $485 \mathrm{~nm}$; emission, $520 \mathrm{~nm}$ ) was measured every $5 \mathrm{~min}$ for $2 \mathrm{~h}$ at $37^{\circ} \mathrm{C}$. Costar black opaque (96 well) plates (Thermo Fisher Scientific, Waltham, MA, USA) were used in the assays. Trolox (Sigma-Aldrich) was used as standard at a range between 0 and $20 i \mathrm{M}$ with a polynomial (second order) curve fit analysis. Mean values (n) 3) of antioxidant capacities were expressed as micromoles of Trolox equivalents (TE) per gram of wet and dry mass (SD).

\section{Ferric reducing antioxidant power}

Ferric reducing antioxidant power (FRAP) values were determined essentially as described previously [24]. Briefly, the reduction of a $\mathrm{Fe}^{3+}-2,3,5$-triphenyltetrazolium (SigmaAldrich) complex in the assay by the antioxidants in the samples was monitored at $593 \mathrm{~nm}$. As a standard, FeSO4 (Sigma-Aldrich) was used, and the FRAP activities of the samples were expressed as the mean $(n=3)$ micromoles of $\mathrm{Fe}^{2+}$ per gram of wet and dry mass (SD).

\section{Antibacterial activity of Aloe vera}

The antibacterial studies were carried out by disc diffusion technique [20]. The sterile nutrient agar plates and potato dextrose agar plates were prepared. The bacterial test organisms like Staphylococcus aureus, Streptococcus pyogenes, Pseudomonas aeruginosa, and Escherichia coli were spread over the nutrient agar plates using separate sterile cotton buds. After the microbial lawn preparation, three different extracts (20 grams of powdered plant materials mixed with $100 \mathrm{ml}$ of various solvents (distilled water, ethanol, and acetone solution)) of plant disc were placed on the organism-inoculated plates with equal distance; control discs were also prepared. All bacterial plates were incubated at $27^{\circ} \mathrm{C}$ for $24 \mathrm{~h}$. The diameter of the minimum zone of inhibition was measured in millimeter. For each test, three replicates were performed.

\section{Results and discussion}

The compounds identified and their quantities in the $A$. vera LGE and ELGE are summarized in Table 1. Of all the compounds identified, the groups of compounds best described for their health benefits are the phenolic acids/ polyphenols, sterols, fatty acids, and indoles. Apart from these, various alkanes, pyrimidines, alkaloids, organic acids, aldehydes, dicarboxylic acids, ketones, and alcohols were also identified. Although the extraction methods used in this study were not selected to target alcohols, a few of these were also identified. One would, however, expect a far larger variety of alcohols to occur in Aloe and in far higher concentrations. For better extraction of these, headspace isolation by simultaneous purging should be used as described previously [25]. However, by employing this method, one would extract far less of the other biologically important health-associated compounds. Therefore, to accomplish the aims of our study, alternative extraction procedures were used as described under the 'Methods' section using ethyl acetate/diethyl ether and hexane.

A general comparison of the phytochemical contents of the LGE and ELGE, calculated per LGE dry mass, shows that with the exception of a few compounds, far fewer compounds and at lower concentrations are extracted from 95\% ethanol extracts than directly from the LGE using ethyl acetate/diethyl ether or hexane. The occurrence of 
Table 1 Concentrations of GC-MS identified compounds from LGE and 95\% ELGE

\begin{tabular}{|c|c|c|c|}
\hline \multirow[b]{2}{*}{ Compound } & \multicolumn{3}{|c|}{ Concentration (ppm) } \\
\hline & LGE (per dry mass LGE) & ELGE (per dry mass LGE & ELGE (per dry mass ELGE) \\
\hline \multicolumn{4}{|l|}{ Phenolic acids/polyphenols } \\
\hline Phenol & 14.32 & 30.12 & $1.3 \times 10^{4}$ \\
\hline Vanillic & 58.60 & 24.34 & $8.5 \times 10^{3}$ \\
\hline Homovanillic & 18.55 & 13.26 & $5.0 \times 10^{3}$ \\
\hline Protocatechuic & 163.21 & 42.33 & $1.6 \times 10^{4}$ \\
\hline 3,4-Dihydroxyphenylacetic & 7.54 & & \\
\hline 5-Methoxyprotocatechuic & 2.5 & & \\
\hline Syringic & 25.54 & & \\
\hline Sinapic & 32.68 & & \\
\hline$p$-Coumaric & 450.87 & & \\
\hline Isoferulic & 52.90 & & \\
\hline Ferulic & 88.67 & 4.2 & $1.5 \times 10^{3}$ \\
\hline Aloe emodin & 87.79 & & \\
\hline 4-Phenyllactic & 11.02 & & \\
\hline 4-Ethylphenol & 10.12 & 32.21 & $1.2 \times 10^{4}$ \\
\hline Hydrocinnamic & 36.50 & & \\
\hline p-Salicylic & 186 & 59.2 & $1.8 \times 10^{4}$ \\
\hline Benzoic & 870.1 & 5,507 & $1.9 \times 10^{6}$ \\
\hline Phenylpyruvic & & 6.50 & $2.3 \times 10^{5}$ \\
\hline Hydro-p-coumaric & 15.31 & & \\
\hline \multicolumn{4}{|l|}{ Alcohols } \\
\hline 2-Butanol & 13.65 & & \\
\hline Glycerol & 340.9 & & \\
\hline Phenylethanol & 86.56 & & \\
\hline \multicolumn{4}{|l|}{ Aldehydes } \\
\hline Benzaldehyde & 56.34 & 72.5 & $2.5 \times 10^{4}$ \\
\hline m-Tolualdehyde & 18.21 & & \\
\hline \multicolumn{4}{|l|}{ Organic acids } \\
\hline Lactic & 148 & 202.1 & $7.1 \times 10^{4}$ \\
\hline Glycolic & 93.1 & & \\
\hline Pyruvic & & 88.1 & $3.1 \times 10^{4}$ \\
\hline Furoic & 57.43 & & \\
\hline Phosphoric & & 341.2 & $1.2 \times 10^{5}$ \\
\hline Succinic & 383 & 117.6 & $4.1 \times 10^{4}$ \\
\hline 2-Methylsuccinic & 62.1 & & \\
\hline Picolinic & & 281 & $9.7 \times 10^{4}$ \\
\hline Malic & 46.7 & & \\
\hline Tartaric & 18.3 & & $6.3 \times 10^{3}$ \\
\hline Isonicotinic & 40.21 & & \\
\hline 2-Hydroxybutyric & & 2.1 & 829.92 \\
\hline \multicolumn{4}{|l|}{ Alkanes } \\
\hline 1,3-Dihydroxybutane & 10.22 & 10.56 & $3.7 \times 10^{3}$ \\
\hline
\end{tabular}




\begin{tabular}{|c|c|c|c|}
\hline \multicolumn{4}{|l|}{ Pyrimidines } \\
\hline Uracil & 697.23 & & \\
\hline Thymine & 429.76 & 189.11 & $6.3 \times 10^{4}$ \\
\hline \multicolumn{4}{|l|}{ Fatty acids } \\
\hline Lauric (C12:0) & 0.32 & & \\
\hline Myristic (C14:0) & 0.74 & & \\
\hline Palmitoleic (C16:1) & 1.32 & 0.19 & 65.70 \\
\hline Linoleic (C18:2 n-6) & 102 & 0.42 & 143 \\
\hline \multicolumn{4}{|l|}{ Indoles } \\
\hline Indole-3-acetic acid & 2.80 & & \\
\hline \multicolumn{4}{|l|}{ Alkaloids } \\
\hline Hypoxanthine & 27.65 & & \\
\hline \multicolumn{4}{|l|}{ Ketones } \\
\hline Acetophenone & 8.02 & & \\
\hline \multicolumn{4}{|l|}{ Sterols } \\
\hline Cholestanol & 24.32 & 12.99 & $4.6 \times 10^{3}$ \\
\hline$\beta$-Sitosterol & $1,604.5$ & & \\
\hline \multicolumn{4}{|l|}{ Dicarboxylic acids } \\
\hline Azelaic & 0.02 & & \\
\hline Undecanedioic & 0.04 & & \\
\hline
\end{tabular}

higher concentrations of a few compounds from the ELGE is most probably due to matrix protein conformation changes and precipitation by the ethanol, hence making extraction of these protein-associated compounds easier [26]. However, when the concentrations are quantified for the individual compounds occurring in the ELGE per dry mass of ELGE, the concentrations for the compounds extracted are approximately 345 times higher than those for the same compounds occurring in the lyophilized LGE. Similarly, higher concentrations of total polyphenols, total flavonoids, and total non-flavonoids, as well as higher antioxidant capacities using ORAC and FRAP analyses (Table 2) are seen in the ELGE extracts. Additionally, these values are again far less when quantified per LGE dry mass. This indicates that from an analytical perspective, 95\% ethanol is in general less effective than direct ethyl acetate/ diethyl ether or hexane extractions (in the case of fatty acids) for the phytochemical characterization of Aloe species. However, the results also indicate the ELGE allows for effective concentration of a number of biologically

Table 2 Concentrations of total polyphenols, flavonoids, and non-flavonoids as well as antioxidant capacity via ORAC and FRAP analyses

\begin{tabular}{|c|c|c|c|c|c|}
\hline Compound & LGE (dry mass) & LGE (wet mass) & $\begin{array}{c}\text { ELGE } \\
\text { (expressed as dry } \\
\text { mass ELGE) }\end{array}$ & $\begin{array}{c}\text { ELGE } \\
\text { (expressed as } \\
\text { dry mass LGE) }\end{array}$ & $\begin{array}{c}\text { ELGE } \\
\text { (expressed as } \\
\text { wet mass } \\
\text { LGE) }\end{array}$ \\
\hline Total polyphenols (mg of GAE/100 g \pm SD) & $78.2 \pm 4.03$ & $2.70 \pm 0.14$ & $413 \pm 9.88$ & $26.8 \pm 0.63$ & $0.93 \pm 0.02$ \\
\hline Total flavonoids (mg of CE/100 g $\pm \mathrm{SD}$ ) & $5.3 \pm 0.38$ & $0.19 \pm 0.01$ & $33.6 \pm 1.98$ & $2.15 \pm 0.13$ & $0.08 \pm 0.003$ \\
\hline $\begin{array}{l}\text { Total non-flavonoids } \\
\text { (by calculation) }\end{array}$ & $73.7 \pm 0.43$ & $2.55 \pm 0.22$ & $378 \pm 6.78$ & $24.5 \pm 1.5$ & $0.86 \pm 0.02$ \\
\hline $\begin{array}{l}\text { ORAC, hydrophilic } \\
\text { (ímol of TE/g) }\end{array}$ & $53 \pm 1.1$ & $1.81 \pm 0.04$ & $136 \pm 2.3$ & $8.83 \pm 0.16$ & $0.30 \pm 0.006$ \\
\hline ORAC, lipophilic (ímol of TE/g) & ND & ND & ND & ND & ND \\
\hline ORAC, total (ímol of TE/g) & $53 \pm 1.1$ & $1.81 \pm 0.04$ & $136 \pm 2.3$ & $8.83 \pm 0.16$ & $0.30 \pm 0.006$ \\
\hline FRAP (ímol/g) & $4.9 \pm 0.25$ & $0.17 \pm 0.07$ & $19.0 \pm 0.3$ & $1.21 \pm 0.02$ & $0.05 \pm 0.001$ \\
\hline
\end{tabular}

Concentrations of total polyphenols, flavonoids, and non-flavonoids as well as antioxidant capacity via oxygen radical absorbance capacity (ORAC) and ferric reducing antioxidant power (FRAP) analyses in lyophilized aloe ferox leaf gel (LGE) and 95\% ethanol leaf gel extracts (ELGE). ND, not detected. 
active ingredients from LGE, confirming its popularity for use for testing biological activity for certain components in vivo and in vitro. Additionally, polyphenols are generally classified into flavonoids and non-flavonoids [27]. In Table 1, GC-MS analyses indicate the majority of the polyphenol compounds identified in the $A$. vera leaf gel belonging to the non-flavonoid group of polyphenols. This was confirmed by the spectrophotometic analysis of polyphenols summarized in Table 2, indicating the non-flavonoid components to contribute to $93 \%$ of the total polyphenols in the LGE and $92 \%$ in the ELGE.

Over the past 10 years, there has been a growing interest in the value of polyphenols among researchers and food manufacturers. This is mainly because of their antioxidant properties, their abundance in our diet, and their role in the prevention of various diseases associated with oxidative stress such as cancer, cardiovascular disease, neurodegeneration [28], and diabetes [29]. Polyphenols constitute a large class of molecules containing a number of phenolic hydroxyl groups attached to ring structures allowing for their antioxidant activities. These compounds are multifunctional and can act as reducing agents, hydrogendonating antioxidants, and singlet oxygen quenchers [27]. All of the individual A. vera leaf gel antioxidant polyphenols identified in Table 1 may contribute to the prevention of the above-mentioned diseases to a greater or lesser extent. The individual contributions of these to disease prevention would, however, depend on their concentrations, antioxidant capacities, bioavailabilities, and specific mechanisms of action. Although the individual phenolic acids/polyphenols occurring in the highest concentrations were benzoic acid, $p$-toluic acid, $p$-coumaric acid, $p$ salicylic acid, protocatechuic acid, hydroxyphenylacetic acid, ferulic acid, aloe emodin, and vanillic acid, it is wellknown that the protective health benefits of polyphenols are mainly through a combination of additive and/or synergistic effects between the individual compounds [30]. Consequently, those polyphenol/phenolic compounds identified in lower concentrations may also be of value. Due to the fact that the majority of the phenolic acids/ polyphenols identified in $A$. vera leaf gel in Table 1 are antioxidants [27] and these compounds as a group occur in the highest concentrations, one would expect these to contribute to the majority of the antioxidant capacity measured in these extracts (Table 2). However, apart from these polyphenols, the indoles [31] and alkaloids identified
[32] are also known to possess antioxidant activities and may consequently also contribute to the ORAC and FRAP values of these extracts. When interpreting the data of this nature, one should keep in mind that using the concentrations of these antioxidant compounds alone is insufficient criteria for making predictions of individual contributions to oxidative stress. As previously described, this is due to the fact that the concentrations of individual polyphenol antioxidants are not the only factor influencing antioxidant capacity; the structural arrangements (number and position of hydroxyl groups, double bonds, and aromatic rings) of these compounds also play a role [27]. Additionally, their individual contributions to ORAC and FRAP may also differ. Due to the FRAP analysis being an indication of the ferric ion reducing power of a compound or mixture and the ORAC analysis indicating the ability of a compound or mixture to scavenge free radicals, the various individual polyphenol components of the mixture may have stronger free radical scavenging abilities than reducing power, or vice versa, dependent on their chemical structures [33]. Phytosterols are another group of compounds that are well-known for their health benefits. Of the four phytosterols identified in Table 1, $\beta$-sitosterol occurred in by far the highest concentrations in the LGE, contributing to $93 \%$ of the total phytosterols identified.

\section{Antibacterial activity}

Antibacterial activity of $A$. vera was analyzed against $S$. aureus, S. pyogenes, $P$. aeruginosa and E. coli. The maximum antibacterial activities were observed in acetone extract $(12 \pm 0.45,20 \pm 0.35,20 \pm 0.57,15 \pm 0.38)$ other than aqueous extract $(0.00,9 \pm 0.54,0.00,0.00)$ and ethanol extract $(7 \pm 0.38,20 \pm 0.36,15 \pm 0.53,0.00)$. Among the three bacterial organisms, maximum growth suppression was observed in S. pyogenes $(20 \pm 0.35)$ and $P$. aeroginosa $(20 \pm 0.57)$ when compared with $S$. aureus $(12 \pm 0.45)$ and $E$. coli $(15 \pm 0.38)$. Results are presented in Table 3. A. vera leaf gel can inhibit the growth of the two gram-positive bacteria Shigella flexneri and Streptococcus progenies [2]. Specific plant compounds such as anthraquinones and dihhydroxyanthraquinones as well as saponins [32] have been proposed to have direct antimicrobial activity.

The ELGE was once again less effective in extracting these compounds, and only cholestanol was identified. However, the levels normalized to dry mass ELGE were

Table 3 Antibacterial activity of Aloe vera

\begin{tabular}{lccccc}
\hline & \multicolumn{4}{c}{ Zone of inhibition $(\mathbf{m m}$ in diameter; mean \pm SD; $\boldsymbol{n}=\mathbf{3})$} \\
\cline { 2 - 6 } Sample number & Extract & Staphylococcus aureus & Streptococcus pyogens & Pseudomonas aeruginosa & Escherichia coli \\
\hline 1 & Aqueous & - & $9 \pm 0.53$ & - & - \\
2 & Ethanol & $7 \pm 0.37$ & $19 \pm 0.36$ & $14 \pm 0.53$ & - \\
3 & Acetone & $12 \pm 0.45$ & $20 \pm 0.35$ & $19 \pm 0.57$ & $14 \pm 0.38$ \\
\hline
\end{tabular}


not insignificant. Phytosterols are best described for their total cholesterol and low-density lipid cholesterol (LDL-C) lowering effects, consequently associated with reducing the risk for cardiovascular disease [26]. As summarized by Devaraj and Jialal [31] evidence for this has been observed in hypercholesterolemic, diabetic, and healthy volunteers. The mechanism proposed by which phytosterols accomplish this is by lowering cholesterol absorption due to the structural similarities these compounds share with cholesterol $[27,29]$. Apart from lowering cardiovascular risk factors associated with diabetes, phytosterols $(\hat{a}$-sitosterol in particular) have been shown to positively affect diabetes by directly lowering fasting blood glucose levels by cortisol inhibition [30]. Additionally, phytosterols have been shown to reduce biomarkers for oxidative stress and inflammation [31], as well as to reduce cancer development by enabling antitumor responses by increasing immune recognition of cancer, influencing hormonal-dependent growth of endocrine tumors, and altering sterol biosynthesis due to the structural similarities of the phytosterols with these compounds and their substrates [32]. Phytosterols have also been shown to directly inhibit tumor growth by slowing cell cycle progression, by induction of apoptosis, and by the inhibition of tumor metastasis [32].

Long-chain polyunsaturated fatty acids (PUFAs) also have important biological functions noted to modulate risks of chronic degenerative and inflammatory diseases, of which the essential PUFAs, linolenic (C18:3 n-3) and linoleic (C18:2 n-6) acids, are best described [30,33]. Both of these were present in the $A$. vera leaf gel extracts, with linoleic acid being the major fatty acid present. However, despite this, the concentrations of these are still very low in comparison to the other compounds identified with possible health benefits and were not even detectable in the lipophilic ORAC analysis. These fatty acids may probably be too low for the $A$. vera leaf gel to contribute to health through its fatty acid composition. In conclusion, the results of this study show that from an analytical perspective, $95 \%$ ethanol is a less efficient solvent for the extraction of the phytochemical components of $A$. vera leaf gel for descriptive purposes as compared to ethyl acetate/diethyl ether or hexane (in the case of fatty acids). Although the $95 \%$ ethanol extracts contain a smaller variety of extracted compounds, their concentrations are, however, approximately 345 times higher than those of the lyophilized $A$. vera leaf gel when quantified as dry mass ELGE extract. This justifies the popularity of the ELGE for applications testing biological efficacy in vivo and in vitro. For the purpose of determining possible biological application, $A$. vera leaf gel was characterized.

\section{Conclusion}

Various phenolic acids/polyphenols, phytosterols, fatty acids, indoles, alkanes, pyrimidines, alkaloids, organic acids, aldehydes, dicarboxylic acids, ketones, and alcohols were identified and quantified. Due to the presence of the antioxidant polyphenols, indoles, and alkaloids, the $A$. vera leaf gel shows antioxidant capacity as confirmed by ORAC and FRAP analyses. Both GC-MS and spectrophotometric analyses show the non-flavonoid polyphenols to contribute to the majority of the total polyphenol content. Due to the occurrence of the polyphenols, phytosterols, and perhaps the indoles present, $A$. vera leaf gel may show promise in alleviating or preventing the symptoms associated with cardiovascular diseases, cancer, neurodegeneration, and diabetes. This may be due to the well-documented lowering effects of these compounds on total cholesterol, LDL-C, and fasting blood glucose. These results support the current use of $A$. vera by both industry and traditional healers for the treatment of the abovementioned diseases. However, further clinical trials regarding these claims are necessary before accurate conclusions regarding these heath benefits can be made.

\section{Competing interests}

The author declare that she has no competing interests.

\section{Acknowledgement}

The financial support of the National Institute of Genetic Engineering and Biotechnology (NIGEB), Iran, was greatly appreciated.

Received: 6 February 2013 Accepted: 3 June 2013

Published: 19 July 2013

\section{References}

1. Dabai YU, Muhammad S, Aliyu BS (2007) Antibacterial activity of anthraquinone fraction of Vitex doniana. Pakistan J Biol Sci:1-3

2. Ferro VA, Bradbury F, Cameron P, Shakir E, Rahman SR, Stimson WH (2003) In vitro susceptibilities of Shigella flexneri and Streptococcus phygenes to inner gel of Aloe barbadensis Miller. Antimicro Chemother 47(3):1137-1139

3. Hamman JH (2008) Composition and applications of Aloe vera leaf gel. Molecules 13:1599-1616

4. Boutagy J, Harvey DJ (1978) Determination of cytosine arabinoside in human plasma by gas chromatography with a nitrogen-sensitive detector and by gas chromatography-mass spectrometry. J Chromatogr 146:283-296

5. Rice-Evans C (2004) Flavonoids and isoflavones: absorption, metabolism, and bioactivity. Free Radical Biol Med 36:827-828

6. Scalbert A, Williamson D (2000) Dietary intake and bioavailability of polyphenols. J Nutr 130:2073S-2085S

7. Liu RH (2000) Supplement quick fix fails to deliver. Food Technol Int 1:71-72

8. Herraiz T, Galisteo J (2004) Endogenous and dietary indoles: a class of antioxidants and radical scavengers in the ABTS assay. Free Radical Res 38:323-331

9. Azam S, Hadi N, Khan NU, Hadi SM (2003) Antioxidant and prooxidant properties of caffeine, theobromine and xanthine. Med Sci Monit 9:325-330

10. Loots D, der Tw V, Jerling FH (2006) Polyphenol composition and antioxidant activity of Kei-apple (Dovyalis caffra) juice. J Agric Food Chem 54:1271-1276

11. Okyar A, Can A, Akev N, Baktir G, Sutlupinar S (2001) Effect of Aloe vera leaves on blood glucose level in type I and type II diabetic rat models. Phytother Res 15:157-161

12. Chithra P, Sajithlal GB, Chandrakasan G (1998) Influence of Aloe vera on the healing of dermal wounds in diabetic rats. J Ethnopharmacol 59:195-201

13. Koo MWL (1994) Aloe vera, antiulcer and antidiabetic effects. Phytother Res 8:461-464

14. Saito H (1993) Purification of active substances of Aloe arborescens Miller and their biological and pharmacological activity. Phytother Res 7:S14-S19

15. Bunyapraphatsara N, Yongchaiyudha S, Rungpitarangsi V, Chokechaijaroenporn O (1996) Antidiabetic activity of Aloe vera L. juice. II. 
Clinical trials in diabetes mellitus patients in combination with glibenclamide. Phytomedicine 3:245-248

16. Reynolds T, Dweck AC (1999) Aloe vera leaf gel: a review update J Ethnopharmacol 68:3-37

17. Choi S, Chung MH (2003) A review on the relationship between Aloe vera components and their biologic effects. Semin. Integrative Med 1:53-62

18. al-Shamaony L, al-Khazraji SM, Twaij SA (1994) Hypoglycaemic effect of Artemisia herba alba. II. Effect of a valuable extract on some blood parameters in diabetic animals. J Ethnopharmacol 43:167-171

19. Rajasekaran S, Ravi K, Sivagnanam K, Subramanian S (2006) Beneficial effects of Aloe vera leaf gel extract on lipid profile status in rats with streptozotocin diabetes. Clin Exp Pharmacol Physiol 33:232-237

20. Singleton VL, Rossi JA (1965) Colorimetry of total phenolics with phospomolybdic-phosphotungstic acid reagents. Am J Enol Vitic 16:144-158

21. Marinova D, Robarova F, Atanassova M (2005) Total phenolics and total flavonoids in bulgarian fruits and vegetables. J UniV Chem Technol Metal 40:255-260

22. Prior RL, Hoang H, Gu L, Wu X, Bacchiocca M, Howard L, Hampsch-Woodill M, Huang D, Ou B, Jacob R (2003) Assays for hydrophilic and lipophilic antioxidant capacity (oxygen radical absorbance capacity (ORAC(FL))) of plasma and other biological and food samples. J Agric Food Chem 51:3273-3279

23. Huang D, Ou B, Hampsch-Woodill M, Flanagan JA, Deemer EK (2002) Development and validation of oxygen radical absorbance capacity assay for lipophilic antioxidants using randomly methylated â-cyclodextrin as the solubility enhancer. J Agric Food Chem 50(7):1815-1821

24. Benzie IF, Strain JJ (1999) Ferric reducing/antioxidant power assay: direct measure of total antioxidant activity of biological fluids and modified version for simultaneous measurement of total antioxidant power and ascorbic acid concentration. Methods Enzymol 299:15-27

25. Umano K, Nakahara K, Shoji A, Shibamoto T (1999) Aroma chemicals isolated and identified from leaves of Aloe arborescens Mill. var. Natalensis Berger. J Agric Food Chem 47:3702-3705

26. Patch CS, Tapsell LC, Williams PG, Gordon M (2006) Plant sterols as dietary adjuvants in the reduction of cardiovascular risk: theory and evidence. Vasc Health Risk Manag 2:157-162

27. Lichtenstein AH, Deckelbaum RG (2001) AHA Science Advisory. Stanol/sterol ester-containing foods and blood cholesterol levels. A statement for healthcare professionals from the Nutrition Committee of the Council on Nutrition, Physical Activity, and Metabolism of the American Heart Association. Circulation 103:1177-1179

28. Normen L, Dutta P, Lia A, Andersson H (2000) Soy sterol esters and â-sitostanol ester as inhibitors of cholesterol absorption in human small bowel. Am J Clin Nutr 71:908-913

29. Jones PJ, Ntanios FY, Raeini-Sarjaz M, Vanstone CA (1999) Cholesterol-lowering efficacy of a sitostanol-containing phytosterol mixture with a prudent diet in hyperlipidemic men. Am J Clin Nutr 69:1144-1150

30. McAnuff MA, Harding WW, Omoruyi FO, Jacobs H, Morrison EY, Asemota HN (2005) Hypoglycemic effects of steroidal sapogenins isolated from Jamaican bitter yam, Dioscorea polygonoides. Food Chem Toxicol 43:1667-1672

31. Devaraj S, Jialal I (2006) The role of dietary supplementation with plant sterols and stanols in the prevention of cardiovascular disease. Nutr Re 64:348-354

32. Bradford PG, Awad AB (2007) Phytosterols as anticancer compounds. Mol Nutr Food Res 51:161-170

33. Simopoulos AP (2006) Evolutionary aspects of diet, the omega-6/ omega-3 ratio and genetic variation: nutritional implications for chronic diseases. Biomed Pharmacother 60:502-507

doi:10.1186/2191-2858-3-5

Cite this article as: Nejatzadeh-Barandozi: Antibacterial activities and antioxidant capacity of Aloe vera. Organic and Medicinal Chemistry Letters 2013 3:5.

\section{Submit your manuscript to a SpringerOpen ${ }^{\circ}$ journal and benefit from:}

- Convenient online submission

- Rigorous peer review

- Immediate publication on acceptance

- Open access: articles freely available online

- High visibility within the field

- Retaining the copyright to your article

Submit your next manuscript at $\gg$ springeropen.com 